\title{
Data rescue of national and international meteorological observations at Deutscher Wetterdienst
}

\author{
F. Kaspar ${ }^{1}$, B. Tinz ${ }^{2}$, H. Mächel ${ }^{1}$, and L. Gates ${ }^{2}$ \\ ${ }^{1}$ Deutscher Wetterdienst, Nationale Klimaüberwachung, Offenbach, Germany \\ ${ }^{2}$ Deutscher Wetterdienst, Maritime Klimaüberwachung, Hamburg, Germany \\ Correspondence to: F. Kaspar (frank.kaspar@dwd.de)
}

Received: 25 January 2015 - Accepted: 10 March 2015 - Published: 17 April 2015

\begin{abstract}
Germany's national meteorological service (Deutscher Wetterdienst, DWD) houses in Offenbach and Hamburg huge archives of historical handwritten journals of weather observations. They comprise not only observations from Germany, but also of the oceans and land stations in many parts of the world. DWD works on the digitization and quality control of these archives. The current status is presented here.
\end{abstract}

\section{Introduction}

The current discussion on climate change goes along with a revival of interest in all sorts of historical climate information. Such data are needed to provide reliable statements on climate change (as e.g. described in Kaspar, 2013 for Germany). Long time series are of high relevance for climate analysis, especially for the analysis of extreme events. They are also needed as input for model-based global and regional reanalysis of past weather patterns (Allan et al., 2011a; Compo et al., 2011; Rennie et al., 2014). Various international efforts therefore try to assure that such historic data do not get lost ("DARE" = "data rescue" activities) and that they are transferred into digital format (Brunet and Jones, 2011; Allan et al., 2011b).

Historic observations are typically available as handwritten documents. Figure 1 shows an example from the archive of DWD. Automatic procedures, like Optical Character Recognition (OCR), are typically not feasible with such documents or would result in too many errors (Brönnimann et al., 2006). In such cases, digitization can only be done by manual key entry and is a labour-intensive activity.

Deutscher Wetterdienst houses archives of historical handwritten journals of weather observations at two locations. They are located in Offenbach and Hamburg and comprise national and worldwide observations:

In Offenbach all German state-owned meteorological observations from the beginning of the Prussian Meteorological Institute in 1848 are archived. The archive in Hamburg holds the archive of the German Naval Observatory, "Deutsche Seewarte", which existed from 1874 to 1945 . It includes marine data records from ships, as well as land stations in many parts of the world (e.g. from former German colonies) and signal stations situated at the coasts of the North and Baltic Sea.

The following sections provide details on these archives and the status of the digitization activities.

\section{The archives with historic weather observations}

\subsection{German climate stations}

Yearbooks, original tables, observer diaries and microfilms from about 2300 climate stations (temperature, precipitation and other parameters) and about 10000 precipitation stations from Germany are stored in the archive.

The stations were operated by the Prussian Meteorological Institute (from 1848 onwards) and other meteorological services. The archive comprises about 340000 years of precipitation and about 45000 years of climate observations. It also contains strips from self-recording barometers, anemo-, hydro-, pluvio- and thermographs from terrestrial stations or pilot balloons. Most of these records are already digitally available, but there are still several records which need to be rescued and digitised.

The calculated volume of paper documents (diaries, tables, etc.) that is stored in the archive amounts to more than $5000 \mathrm{~m}$. It also includes nearly one million postcards 


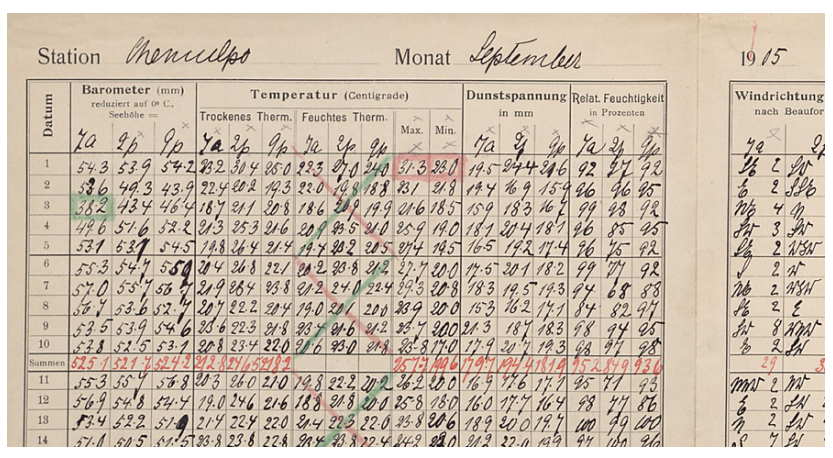

Figure 1. Handwritten observations of Chemulpo (South Korea, $37^{\circ} 28^{\prime} \mathrm{N}, 126^{\circ} 38^{\prime} \mathrm{E}$ ) from September 1905.

with daily precipitation observations and weather phenomena records from voluntary precipitation stations (one postcard per calendar month). In addition, there are 190 rolls of film in the Central Archive (each with 800-1000 images per roll). These films were made in the early 1940s and contain copies of original climate station records which to a large part were destroyed during the end of the Second World War (Wege, 2002).

The history of the observational network in Germany is determined by the diversity of political units until 1918 (Kingdoms, Duchies, Princedoms etc.) and also the diversity of meteorological services. From 1848-1933 nine meteorological/hydrological services and other institutions existed simultaneously. Consequently the observational times, instructions, instruments and practices were heterogeneous. An observational standard was established in 1936 when the voluntary observers were trained by the staff of the weather service. After World War II two different meteorological services existed (responsible for the western and eastern parts of Germany).

The historic archive with the observations until 1945 from stations located within the German borders of 1936 was located in the western part of Germany. Only few copies of these historic observations were delivered to the meteorological service of the eastern part. Therefore the digitally available daily meteorological records from climate stations typically start after World War II in the eastern part. Time series of precipitation are available for a larger number of stations. These series are fully available in digital form from year 1969 onwards. Before that year only approximately half of the total number of stations were available in digital form for the eastern part. In the western part of Germany a large number of series start in 1931 for precipitation and in 1941 for the other climatological variables.

In 2004 the Deutscher Wetterdienst started a new initiative to digitize additional historical daily documents from land stations for Germany (project name "KLIDADIGI"). The aim of this project was to fill the gaps in the eastern part of Germany after World War II and to extend the num-

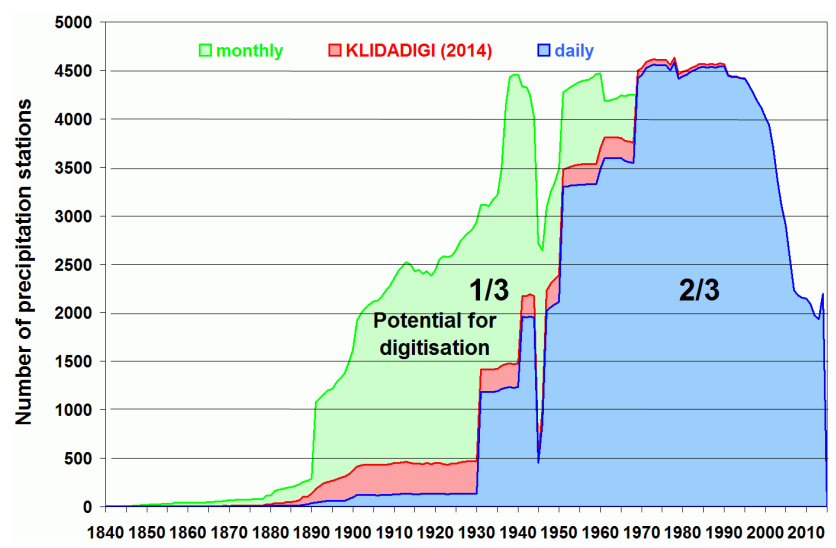

Figure 2. Temporal evolution of the digitally available precipitation series and of the digitized records until the end of 2014 (the potential for digitization is the portion of the digitized monthly data that is not yet available as digital daily data).

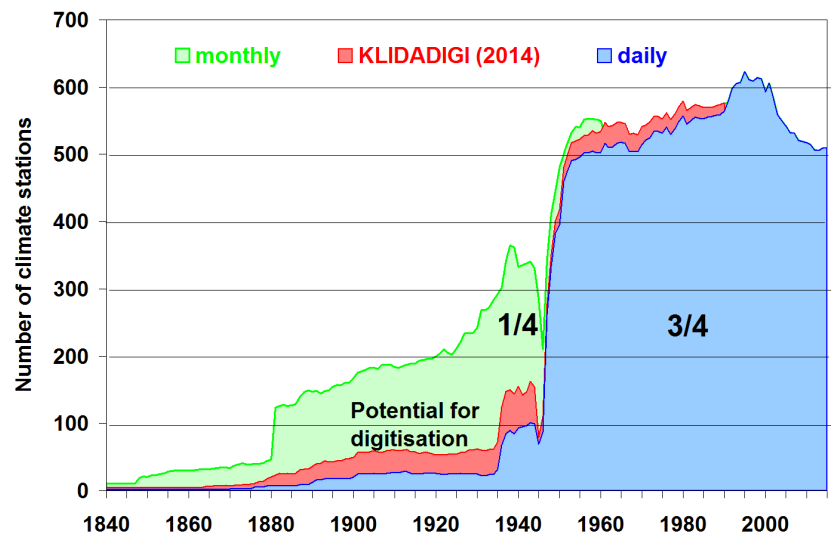

Figure 3. Temporal evolution of the digitally available temperature series and of the digitized records until the end of 2014 (the potential for digitization is the portion of the digitized monthly data that is not yet available as digital daily data).

ber of stations with 100 years of daily records (for details see Mächel et al., 2009). Figures 2 and 3 show the status of the digitally available data before the start of the project and the status at the end of 2014. Figure 2 shows the temporal evolution of the digitally available precipitation data for daily and monthly resolutions together with the digitization potential for the period 1840 to the end of 2014. Similarly Fig. 3 shows the temporal distribution of the digitally available temperature records. Assuming that all monthly data are already digitized and the corresponding daily recordings are available on paper we can estimate the potential for digitization as the difference between the number of stations with digitally available monthly and daily data.

At the end of the year 2014 about $5.0 \%$ of all the available precipitation records (or $12.8 \%$ of the total not yet digitized potential) and $5.9 \%$ of the climate records (or $15.3 \%$ of the total potential) were digitized within this activity (Fig. 4). It 

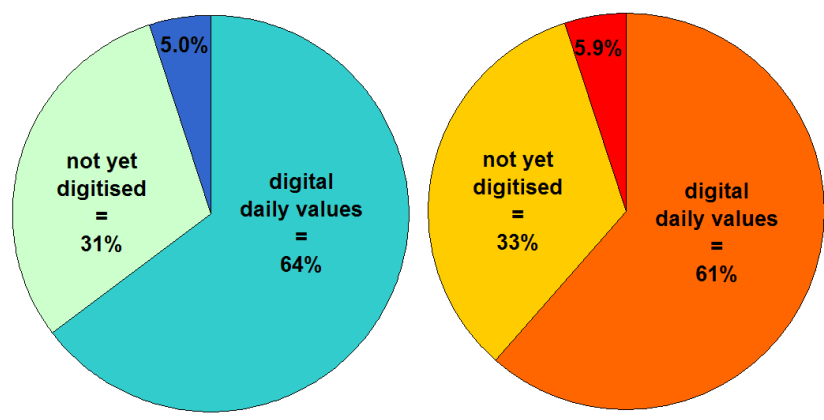

Figure 4. Fraction of the digitally available daily data, the data not yet digitized (the potential for digitization) and the amount digitized data by the KLIDADIGI initiative until the end of 2014 of the entire amount of data for precipitation (left) and temperature (right) series.

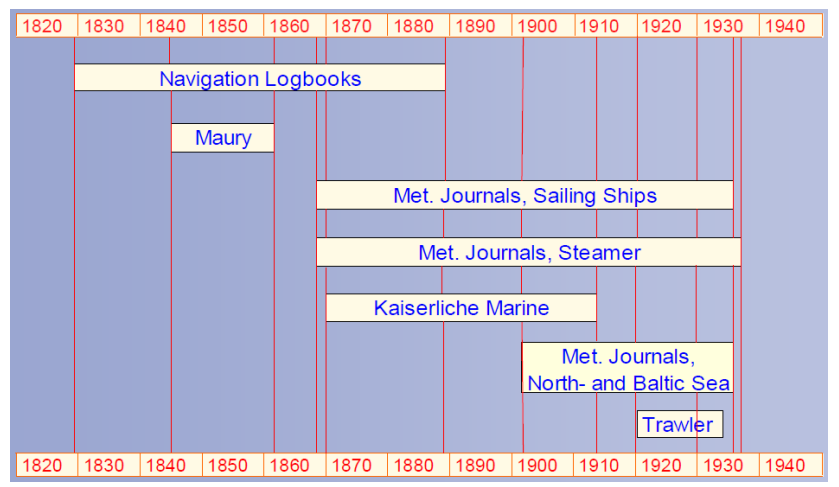

Figure 5. Data sources of ship-based weather observations of German Naval Observatory Hamburg.

is expected that in the next 11 years about the same amount of data could be digitized, that is nearly a quarter of the potential. To complete this task about 100 person-years are needed (200 person-years for the whole project).

\subsection{Ship observations}

The data of the marine archive in Hamburg were collected by the German Naval Observatory ("Deutsche Seewarte"). It includes millions of data records from sailing ships, steamers and light vessels. The oldest go back to the 18 th century. In total there are about 37000 meteorological logbooks in the Hamburg archive of DWD. These logbooks had been given to German ships to collect weather information during their voyages.

The collection started in 1876 and continued until World War II. Figure 5 shows the data sources. The digitization of selected parameters started already in the 1940s with punched cards with focus on the Atlantic. Since 2008 the digitization is continued within an internal project. The status is shown in Fig. 6. The data from the North and South Atlantic is already digitized.

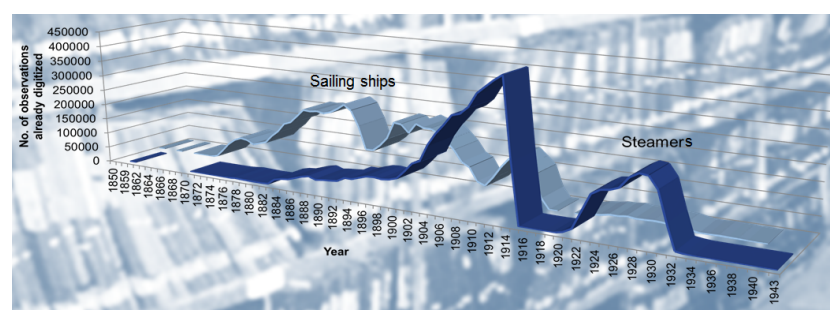

Figure 6. Number of digitized observations from sailing ships and steamers of the German Naval Observatory Hamburg (in total 15.1 million out of approx. 21 million at the time of writing).

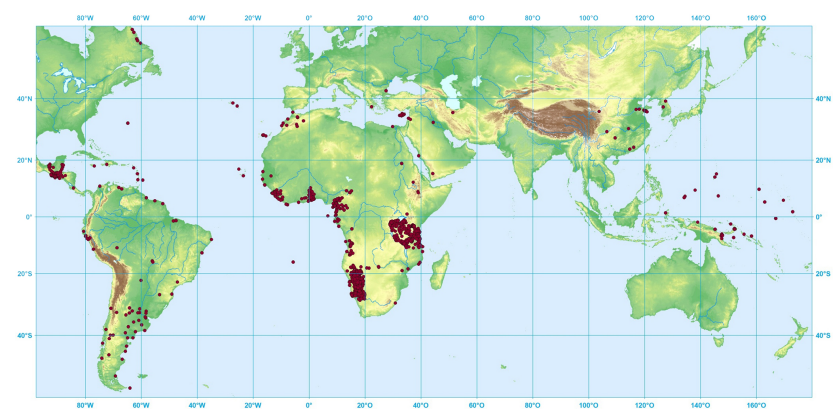

Figure 7. Position of overseas stations of German Naval Observatory Hamburg 1830-1944.

\subsection{Overseas stations}

Figure 7 shows the geographical position of the more than 1550 historical land stations of the German Naval Observatory in many parts of the world. They are situated in Africa, the Americas, China and some isles in the tropical Pacific with a high concentration of the stations in the former German colonies. Climate journals from about 650 stations include precipitation, temperature and weather data and other parameters. At about 900 stations only precipitation was measured. Data are available for the period 1830-1944 (Fig. 8). The typical length of these time series is about 1 to 10 years. Some stations cover over 20 years.

The handwritten records of 195 stations (12\%) in China, the tropical Pacific, Cameroon, Togo and Tanzania have been digitized so far. Original documents of Quindao (China) were handed over to China Meteorological Administration (CMA) in Quindao in 2014.

\subsection{Signal stations at the coasts of the North and Baltic Sea}

The German Naval Observatory also performed weather observations at coastal signal stations. The archive of the signal stations in Hamburg consists of about 800 handwritten journals with observations spanning a 123 years period, starting in 1877 and ending in 1999. Figure 9 shows the locations on German coasts of the North and Baltic Seas. As the wind conditions were of particular interest to sailors, all records 


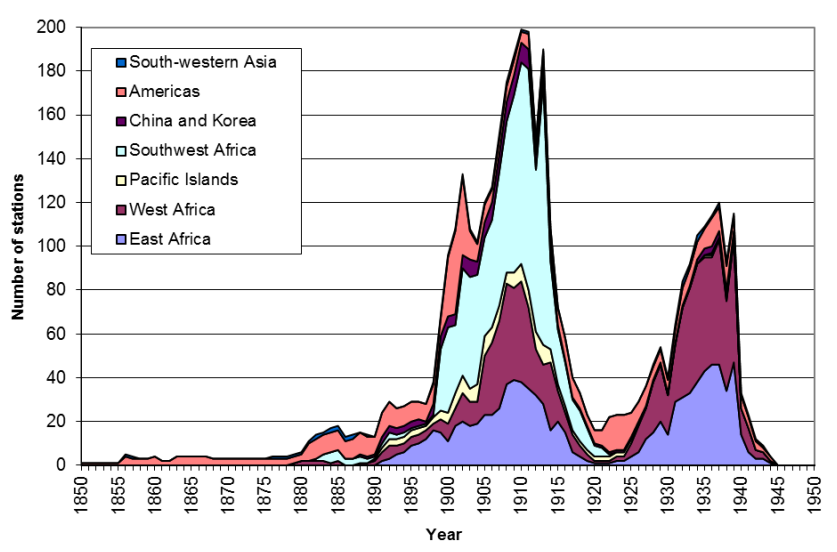

Figure 8. Number of overseas stations of German Naval Observatory Hamburg in specific world regions.

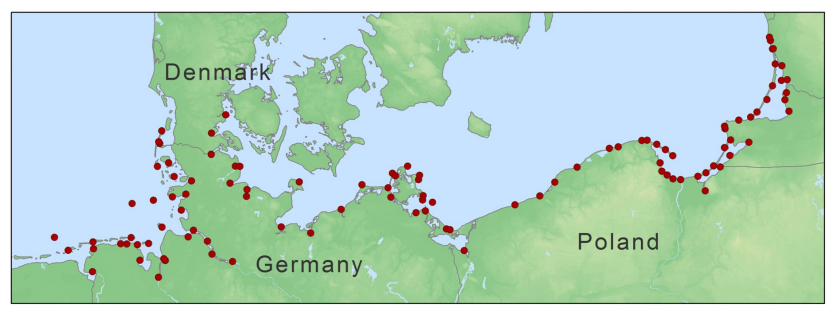

Figure 9. Positions of signal stations of the German Naval Observatory Hamburg 1877-1999.

contain values of wind force and wind direction, but there are also details of the weather conditions and visibility and before 1940 there are also sea level pressure and precipitation data and in some cases sea state was recorded. Most stations reported 3 to 9 times per day, the pressure was usually measured at least once per day and the precipitation twice. During stormy days, observation frequencies were often increased.

The number of the stations changed throughout the years with a maximum of nearly 100 stations from 1920 to 1940.

To date, the handwritten journals of the period 1969 to 1999 have been digitised (about $20 \%$ of the archive). For the period $1877-1968$ a selection of 15 stations is in the process of digitization.

If the location of the station is nowadays in Denmark, Poland, Russia or Lithuania, the data will be forwarded to the National Meteorological Service of the respective country after digitisation.

\section{Application examples, data access and international cooperation}

Long time series of meteorological observations are important information for understanding long term climate trends. The scientific value of the newly digitized daily data from German stations has for example been demonstrated in the study of Brienen et al. (2013). By comparing the first and second half of the 20th century, they have shown that these are characterized by partly opposite trends in precipitation indices. The extended data base is also used for the long term analysis of climate trends in Germany. This analysis is performed for the period from 1881 to today and has been updated in 2012 based on the increased density of stations, esp. in the north-east of Germany (Kaspar et al., 2013).

After digitization, the time series are quality controlled (e.g. Mächel and Kapala, 2013) and incorporated into the regular climate data base of DWD. Since 2014 the time series of German stations are freely available and can be downloaded from an FTP-Server of DWD's Climate Data Center (http://www.dwd.de/cdc; ftp://ftp-cdc.dwd.de/pub/CDC).

DWD also supports international initiatives by providing data from the historic archives. One example is the Southern African Science Service Centre for Climate Change and Adaptive Land Management (SASSCAL; http://www. sasscal.org), a joint initiative of Angola, Botswana, Namibia, South Africa, Zambia, and Germany. DWD supports the data management and data rescue activities of the meteorological services in the region, e.g. by providing data from its historical archives but also by providing training related to data rescue and management. Digitized data are also provided to initiatives like the International Surface Temperature Initiative (ISTI; www.surfacetemperatures.org), the Atmospheric Circulation Reconstructions over the Earth (ACRE), the International Comprehensive Ocean-Atmosphere Data Set (ICOADS; http://icoads.noaa.gov/) and to European projects that will use the data for reanalysis-related activities in the context of the COPERNICUS Climate Change Service (http: //www.copernicus.eu).

Original historic documents with phenological observations (Kaspar et al., 2014) have been handed over to the Austrian and Czech meteorological services. Digitized data of 13 land stations have been provided to the China Meteorological Administration (CMA) and data of signal stations at the Polish coast were given to the Institute of Meteorology and Water Management (IMWG).

Documents from two colonial stations (Edea and Ngeme in Cameroon) were provided to the "Data Rescue @ Home"project in order to explore the possibility of contributions to the digitization effort from volunteers who are interested in climate or historic weather data. This web-based citizen science project has been developed at the ETH Zurich and the Oeschger Centre for Climate Change Research (http: //www.data-rescue-at-home.org/). Digital images of the observations are shown together with an entry masks that resemble the origin structure of the tables. The digitized time series of these two stations were of very good quality. Such voluntary contributions might therefore be a helpful contribution to the overall digitization effort. 
Acknowledgements. The authors would like to thank the reviewers and all those who were and are involved in our data rescue activities.

Edited by: I. Auer

Reviewed by: R. Allan and three anonymous referees

\section{References}

Allan, R., Brohan, P., Compo, G. P., Stone, R., Luterbacher, J., and Brönnimann, S.: The International Atmospheric Circulation Reconstructions over the Earth (ACRE) Initiative, B. Am. Meteorol. Soc., 92, 1421-1425, 2011a.

Allan, R., Compo, G., and Carton, J.: Recovery of Global Surface Weather Observations for Historical Reanalyses and International Users, Eos Trans. AGU, 92, 154, doi:10.1029/2011EO180008, 2011b.

Brienen, S., Kapala, A., Mächel, H., and Simmer, C.: Regional centennial precipitation variability over Germany from extended observation records, Int. J. Climatol., 33, 2167-2184, doi:10.1002/joc.3581, 2013.

Brönnimann, S., Annis, J., Dann, W., Ewen, T., Grant, A. N., Griesser, T., Krähenmann, S., Mohr, C., Scherer, M., and Vogler, C.: A guide for digitising manuscript climate data, Clim. Past, 2, 137-144, doi:10.5194/cp-2-137-2006, 2006.

Brunet, M. and Jones, P.: Data rescue initiatives: bringing historical climate data into the 21 st century, Clim. Res., 47, 29-40, doi:10.3354/cr00960, 2011.

Compo, G. P., Whitaker, J. S., Sardeshmukh, P. D., Matsui, N., Allan, R. J., Yin, X., Gleason, B. E., Vose, R. S., Rutledge, G., Bessemoulin, P., Brönnimann, S., Brunet, M., Crouthamel, R. I., Grant, A. N., Groisman, P. Y., Jones, P. D., Kruk, M., Kruger, A. C., Marshall, G. J., Maugeri, M., Mok, H. Y., Nordli, Ø., Ross, T. F., Trigo, R. M., Wang, X., Woodruff, S. D., and Worley, S. J.: The Twentieth Century Reanalysis Project, Q. J. Roy. Meteorol. Soc., 137, 1-28, 2011.
Kaspar, F., Müller-Westermeier, G., Penda, E., Mächel, H., Zimmermann, K., Kaiser-Weiss, A., and Deutschländer, T.: Monitoring of climate change in Germany - data, products and services of Germany's National Climate Data Centre, Adv. Sci. Res., 10, 99-106, doi:10.5194/asr-10-99-2013, 2013.

Kaspar, F., Zimmermann, K., and Polte-Rudolf, C.: An overview of the phenological observation network and the phenological database of Germany's national meteorological service (Deutscher Wetterdienst), Adv. Sci. Res., 11, 93-99, doi:10.5194/asr-11-93-2014, 2014.

Mächel, H. and Kapala, A.: Multivariate testing of spatio-temporal consistence of daily precipitation records, Adv. Sci. Res., 10, 8590, doi:10.5194/asr-10-85-2013, 2013.

Mächel, H., Kapala, A., Behrendt, J., and Simmer, C.: Rettung historischer Klimadaten in Deutschland: das KLIDADIGI-Projekt des DWD, Klimastatusbericht 2009 des DWD, 2009.

Rennie J. J., Lawrimore, J. H., Gleason, B., Thorne, P. W., Morice, C. M., Menne, M. J., Williams, C. N., Gambi de Almeida, W., Christy, J., Flannery, M., Ishihara, K., Kamiguchi, K., KleinTank, A. M. G., Mhanda, A., Lister, D., Razuvaev, V., Renom, M., Rusticucci, M., Tandy, J., Worley, S., Venema, V., Angel, W., Brunet, M., Dattore, B., Diamond, H., Lazzara, M., Le Blancq, F., Luterbacher, J., Mächel, H., Revadekar, J., Vose, R., and Yin, $\mathrm{X}$.: The international surface temperature initiative global land surface databank: monthly temperature data release description and methods, Geosci. Data J., 1, 75-102, doi:10.1002/gdj3.8, 2014.

Wege, K.: Die Entwicklung der meteorologischen Dienste in Deutschland, in: Geschichte der Meteorologie in Deutschland, Deutscher Wetterdienst, 2002. 